Methods My Sexuality Matters, a re-orientation base programming was employed to reach out to youth early with sexual health prevention messages through the parents. Parent-child communication, we developed and rigorously evaluated program that enables parents to help shape their children's decisions about sexual behaviour. My sexuality Matters (MSM) is base on intervention provided directly by parents who are care givers of children; this gives parents knowledge and skills to communicate about sexuality with their children. Lesson Learnt: Significant cultural taboos exist in Nigeria that bars parents from speaking with children about sexuality and sexual decision making. Additional challenges include rites of passing rituals, and cultural Challenges that the altered the context of sexuality education. Despite these challenges, over 40000 Nigerian families have participated in My Sexuality Matters (MSM), and the program has been adopted by other countries and many families have continued embracing MSM initiatives.

Conclusion The success of MSM demonstrates that programmes involving parents as sexuality educators and motivators can be implemented and embraced and reduce to the vulnerability of adolescent, youths to STIs. The willingness of parents to rebrand the cultural norms to protect their children's sexual health.

\section{P2-S1.04 ASSOCIATIONS OF SYMPTOMS OF DEPRESSION WITH MULTIPLE SEXUAL RISK BEHAVIOURS IN NOVA SCOTIA ADOLESCENTS}

doi:10.1136/sextrans-2011-050108.282

${ }^{1} \mathrm{D}$ Langille, ${ }^{1} \mathrm{M}$ Asbridge, ${ }^{2} \mathrm{~S}$ Kisely. ${ }^{1}$ Faculty of Medicine, Dalhousie University, Halifax, Canada; ${ }^{2}$ Faculty of Medicine, University of Queensland, Brisbane, Australia

Background While depression is associated with sexual risk taking in adolescents, Canadian studies are few, many studies have not controlled for other risk factors, and none has examined associations of depression with having multiple sexual risks. We tested associations between multiple sexual risk taking and risk of depression while controlling for other salient factors in high school students in Cape Breton, Nova Scotia, Canada.

Methods We surveyed sexually active male $(n=418)$ and females $(\mathrm{n}=467)$ adolescents aged 15-19. Participants were asked about their risk of depression, perception of trust and helpfulness at school (social capital), sexual behaviours, substance use and sociodemographic factors. Logistic regressions were carried out to determine associations of depression with various levels of sexual risk-taking (none, one or two or more).
Results In unadjusted models depression predicted having two or more vs no sexual risk behaviours among both males and females. After controlling for other variables risk of depression remained significantly associated with having two or more sexual risks vs no risks for both males and females [RR Ratios 2.5 (95\% CI 1.4 to 4$)$ and 3.5 (95\% CI 1.6 to 7.82$)$ respectively] and in relation to one vs no risks for females $(R R R=1.9 ; 95 \%$ CI 1.1 to 3.5).

Conclusions These consistent and independent associations of depression risk with multiple sexual risk-taking behaviours should lead healthcare workers interacting with adolescents to consider asking about sexual risk behaviours or testing for sexually transmitted infections among patients showing symptoms of depression. Alternatively, patients engaging in sexually risk taking might be screened for depression.

\section{P2-S1.05 PARENTAL ACCEPTABILITY OF CONTRACEPTIVE METHODS OFFERED TO THEIR TEEN DURING A CONFIDENTIAL HEALTHCARE VISIT}

doi:10.1136/sextrans-2011-050108.283

${ }^{1} \mathrm{~L}$ Hartman, ${ }^{1} \mathrm{M}$ A Shafer, ${ }^{1} \mathrm{~L}$ Pollack, ${ }^{2} \mathrm{C}$ Wibbelsman, ${ }^{1} \mathrm{~F}$ Chang, ${ }^{1} \mathrm{~K}$ Tebb. ${ }^{1}$ University of California San Francisco, San Francisco, USA; ${ }^{2}$ Kaiser Permanente, USA

Background STIs remain epidemic among teens. Parents have a powerful influence on their teens' sexual behaviours, yet their role in preventing adolescent STIs and unplanned pregnancies has been largely ignored in clinical practice and research.

Objective To explore parental acceptability of different contraceptive methods, including condoms, offered to their teen during a confidential healthcare visit (CV).

Methods A cross-sectional phone survey of 261 randomly selected parents/caregivers of girls 12-17 years enrolled in two large diverse clinic systems. Parental acceptability of 7 different contraceptive methods was assessed on a 4-point likert scale (1=very unacceptable to $4=$ very acceptable). We examined if parental acceptability varied according to a variety of demographic factors, perceived likelihood of teen's sexual activity, and parental knowledge of STIs using bivariate analyses $\left(\chi^{2}\right.$ for categorical correlates, $t$ tests for continuous correlates).

Results Parents surveyed were 27-69years old (mean $45 \mathrm{yrs}$ ), $70 \%$ married; $86 \%$ female; and diverse (46\% Latino, 23\% White, $16 \%$ Black, $11 \%$ Asian, 3\% Other). 15\% of household incomes were $\$ 20 \mathrm{~K}$ or less and $25 \%$ over $\$ 100 \mathrm{~K} .36 \%$ attended religious

Abstract P2-S1.04 Table 1 Adjusted multinomial regression of cumulative sexual risk-taking, depression risk and other correlates for males and females (RRs and $95 \% \mathrm{Cl}$ 's)

\begin{tabular}{|c|c|c|c|c|c|c|}
\hline & \multicolumn{2}{|c|}{ One sexual risk vs no sexual risks } & \multicolumn{2}{|c|}{ Two or more sexual risks vs no sexual risks } & \multicolumn{2}{|c|}{ Two or more sexual risks vs one sexual risk } \\
\hline & Females $(n=418)$ & Males $(n=382)$ & Females $(n=418)$ & Males $(n=382)$ & Females $(n=418)$ & Males $(n=382)$ \\
\hline $\begin{array}{l}\text { Alcohol binge } \geq 3 \text { times } \\
\text { in past month }\end{array}$ & $1.7(1.0 \text { to } 3.2)^{*}$ & $1.6(0.9$ to 3.2$)$ & $3.5(2.0$ to 6.4$) \neq$ & $5.3(2.9$ to 9.6$) \neq$ & $2.0(1.2 \text { to } 3.5)^{* * *}$ & $3.3(1.9 \text { to } 5.8)^{* * *}$ \\
\hline $\begin{array}{l}\text { Marijuana use } \geq 3 \text { times } \\
\text { past month }\end{array}$ & $3.2(1.5$ to 7.0$) \dagger$ & $1.2(0.6$ to 2.5$)$ & $3.6(1.7$ to 7.7$) \ddagger$ & $3.5(1.9$ to 6.7$) \neq$ & $1.1(0.6$ to 2.0$)$ & $2.9(1.6 \text { to } 5.4)^{* * * *}$ \\
\hline Not living with both parents & $0.7(0.4$ to 1.2$)$ & $0.9(0.5$ to 1.7$)$ & $1.1(0.6$ to 1.8$)$ & $1.2(0.7$ to 2.2$)$ & $1.6(0.9$ to 2.7$)$ & $1.3(0.7$ to 2.4$)$ \\
\hline Lower family wealth & $0.26(0.1 \text { to } 0.8)^{*}$ & $0.9(0.3$ to 2.9$)$ & $0.7(0.3$ to 1.6$)$ & $0.6(0.2$ to 1.8$)$ & $2.8(0.8$ to 9.0$)$ & $0.6(0.2$ to 1.6$)$ \\
\hline First vaginal sex at age $<15$ & $1.8(0.9$ to 3.6$)$ & $1.3(0.6$ to 2.6$)$ & $5.1(2.6$ to 9.9$) \neq$ & $1.1(0.6$ to 2.2$)$ & $2.8(1.5 \text { to } 5.2)^{* * *}$ & $0.9(0.5$ to 1.6$)$ \\
\hline Last partner $>2$ years older & $1.0(0.6$ to 1.7$)$ & $0.7(0.2$ to 2.4$)$ & $0.8(0.5$ to 1.4$)$ & $1.6(0.6$ to 4.3$)$ & $0.8(0.5$ to 1.4$)$ & $2.3(0.7$ to 7.3$)$ \\
\hline Average school grade $<80 \%$ & $1.2(0.7$ to 2.0$)$ & $2.0(1.1 \text { to } 3.6)^{*}$ & $1.6(0.9$ to 2.8$)$ & $2.4(1.3$ to 4.4$) \dagger$ & $1.4(0.9$ to 2.3$)$ & $1.2(0.6$ to 2.3$)$ \\
\hline Low perceived trust & $1.5(0.9$ to 2.7$)$ & $1.4(0.7$ to 2.9$)$ & $2.0(1.1 \text { to } 3.7)^{*}$ & $1.2(0.6$ to 21$)$ & $1.3(0.7$ to 2.3$)$ & $0.78(0.4$ to 1.4$)$ \\
\hline Low perceived helpfulness & $1.1(0.7$ to 2.0$)$ & $1.0(0.4$ to 1.9$)$ & $1.5(0.9$ to 2.6$)$ & $1.5(0.7$ to 2.9$)$ & $1.3(0.7$ to 2.2$)$ & $1.6(0.8$ to 3.1$)$ \\
\hline $\begin{array}{l}\text { Depression risk } \\
\text { positive screen }\end{array}$ & $1.9(1.1 \text { to } 3.5)^{*}$ & $2.0(0.8$ to 4.8$)$ & $2.5(1.4$ to 4.5$) \neq$ & $3.5(1.6$ to 7.82$) \neq$ & $1.3(0.7$ to 2.4$)$ & $1.6(0.8$ to 3.3$)$ \\
\hline
\end{tabular}

